VARIA 


\title{
Pensamento e fabulação no romance: uma leitura de Osman Lins
}

Claudio Alexandre de Barros Teixeira Universidade de São Paulo

\begin{abstract}
Rainha dos Cárceres da Grécia, último romance de
Osman Lins, publicado em 1976, é uma narrativa
construída na forma de diário, modalidade ficcional já praticada por autores como Machado de Assis (Memorial de Aires), Goethe (Werther) e André Gide (Sinfonia Pastoral), autores citados pelo próprio narrador no romance. Porém, enquanto aqueles livros "ocupavam-se todos de mulheres - de Carlota, de Fidélio, de Gertrudes (...) meu herói é um livro" (LINS, 2005, p. 14).
\end{abstract}

Osman Lins afasta-se das convenções do gênero, como a suspeita de infidelidade e o triângulo amoroso, e faz do diário um espaço para a discussão da própria arte romanesca. A estratégia textual é representada pela ação do narrador de analisar o único romance escrito por sua falecida amante, Júlia Marquezim Enone, que se chama, justamente, A Rainha dos Cárceres da Grécia, o mesmo título do livro de Osman Lins. Esta é, portanto, uma obra metalinguística, um romance sobre um romance, e ainda uma sátira a certos métodos de leitura e interpretação de textos que derivam do estruturalismo francês.

Em vez de apresentar e desenvolver conceitos e argumentos à maneira do ensaio acadêmico, o autor, que assume também os papéis de narrador e personagem sem nome, escolheu expor o seu pensamento dentro da fabulação, utilizando instrumentos 
como o dialogismo, a alegoria, a alusão, a citação, a colagem, a paródia e outras formas intertextuais. O livro não se propõe apenas a narrar uma história, é também um romance intelectual, que cumpre uma função de crítica literária.

O caráter analítico está imbricado à ficção, mistura-se aos personagens, intriga, peripécias e mesmo à técnica compositiva do livro, que parodia recursos da literatura de vanguarda como a estética do fragmento e a escrita cifrada ou enigmática. $\mathrm{O}$ aparente diário pessoal assume uma forma híbrida, que incorpora outras modalidades de texto, como a carta, o versículo bíblico, a referência erudita, o verbete de dicionário, a letra de música, a nota de rodapé, o artigo de jornal, e mescla o discurso ficcional a diversos outros discursos, como o sociológico, o político, o jornalístico e o radiofônico.

O livro não tem uma sequência linear: há um contraponto entre unidades com o foco narrativo expresso na primeira pessoa, em que o narrador analisa o livro de Júlia Marquezim Enone, e unidades com o foco narrativo na terceira pessoa, que são trechos ou resumos de capítulos do próprio romance analisado. Dizendo de outra maneira: as passagens em primeira pessoa são de ordem reflexiva, e aquelas em terceira pessoa descrevem ações, embora a fronteira entre ambas seja porosa, permitindo intersecções (não raro, a voz do narrador se manifesta na descrição da história).

Entre estas unidades o autor inseriu colagens intertextuais com fragmentos de reportagens publicadas nos jornais $O$ Estado de S. Paulo, Jornal do Brasil, Jornal da Tarde e na revista Realidade, citações de autores reais ou fictícios como Lewis Carroll, Sérgio Sant'Anna e a própria Júlia Marquezim Enone (cartas, apontamentos e trechos do romance escrito por ela). As citações e referências aparecem também dentro das unidades narradas em primeira pessoa, com as vozes de Nietzsche, Goethe, Pound, Stendhal, Anaximandro de Mileto e outros dialogando com o narrador. 
As citações não são fortuitas: os artigos publicados na imprensa colaboram para esmiuçar o quadro histórico e social em que foi escrito o romance (com ênfase na situação precária do urbanismo na periferia, na ineficiência dos serviços de saúde pública e da previdência social e na violência praticada pela polícia), e se relacionam com a própria saga de Maria de França, a anti-heroína do livro (realçando o vínculo proposto pelo autor entre literatura e realidade).

As citações literárias, por sua vez, têm função metalinguística, e interagem de maneira dialógica com as reflexões do narrador sobre os princípios da fabulação. Além das frases de autores célebres (que, recortadas de seu contexto original e inseridas em outro adquirem novas possibilidades de leitura), Osman Lins também faz referências a obras obscuras, verídicas ou inventadas, como o Almanaque Cabeça de Leão e Die Hand Zusammenfassung der Welt (A mão, resumo do mundo), de J. O. von Hellwig, que nos remete ao estilo irônico de Jorge Luis Borges, que simulava o saber erudito pela citação de obras pouco conhecidas pelo leitor médio (como a História Natural, de Plínio) e outras apócrifas.

Todas as unidades narrativas do romance, expressas em primeira ou terceira pessoa (que podemos chamar, de maneira sintética e talvez imprecisa, de Pensamento e Fabulação), são antecedidas pela afixação de datas, que conferem ao conjunto uma aparente estrutura de diário (embora seja um diário híbrido): o primeiro registro tem a data de 26/04/1974; o último, de 23/10/1975, num total de 91 registros. Podemos recordar, aqui, o conceito de código cronológico, definido por Roland Barthes como "puro efeito de realidade: o número conota enfaticamente a verdade do fato: aquilo que é preciso é reputado como real (ilusão, aliás, porque existe, bem se sabe, um delírio dos números)" (CHABROL, 1977, p. 46).

A simulação da realidade pela definição temporal é característica da forma do diário, e a escolha dessa estrutura 
não foi casual no romance, pois permite ao autor / narrador / personagem expor o seu pensamento de maneira mais livre e informal do que seria possível em um ensaio, e ao mesmo tempo inserir-se num contexto histórico. Conforme escreve Osman Lins, usando a persona do amante e hermeneuta da romancista morta, "todo ensaio literário, obediente a uma convenção que firmou autoridade, evoca o narrador oculto. Inviável (...) o discurso chamado pessoal - que precisa as circunstâncias da enunciação" (LINS, 2005, p. 14).

Desejando explicitar a proximidade afetiva e intelectual entre o narrador e Júlia Marquezim Enone, resolve adotar outro caminho:

Quero um ensaio onde, abdicando da imunidade ao tempo e, em conseqüência, da imunidade à surpresa e à hesitação, eu estabeleça com o leitor - ou cúmplice - um convívio ideal. Que outra opção, neste caso, impõe-se mais naturalmente que o diário? (idem).

Este discurso pessoal, que funciona como índice de subjetividade do autor e do personagem, é o motivo condutor que permeia todo o romance. Longe de ser um mero artifício literário, que responde de maneira irônica à interdição do narrador onisciente por teóricos como Barthes e Todorov, o uso constante do eu permite ao escritor apresentar suas opiniões pessoais, inseridas no interior da ficção de maneira dialógica e podemos recordar aqui obras como o Sermão da Terceira Dominga do Advento, do Padre Antônio Vieira, que utilizaram o mesmo procedimento: a crítica dentro do discurso de um discurso anterior a ele. No caso do jesuíta, seu sermão era uma resposta ao pensamento aristocrático de que a nobreza era "algo ontológico, um valor herdado pelo nascimento", como escreve José Luís Fiorim (BRAIT, 2006, p. 175); no caso do romancista, ele utiliza recurso similar para se contrapor às teses 
estruturalistas, em voga nos círculos acadêmicos. No apontamento de 18/05/1974 de seu diário, o narrador/ personagem diz:

Revela-me A. B., com seu fino sorriso eclesiástico, o que sucede com alunos seus e até com mestres de nome: se, por exemplo, sabem alguma coisa de Madame de Volanges, de Danceny e do libertino Valmont, não é por terem lido As ligações perigosas, e sim porque ouviram a análise estampada há cerca de oito anos na revista Communications sobre o romance de Laclos (...). O editor, hoje, acrescenta A. B., ao publicar um estudo literário, dispõe de um público importante, ávido, mais numeroso que o público - real ou possível - da obra analisada e que talvez nem julgue necessário conhecê-la. Adverte-me, em compensação, para o lado negativo do que podia ser uma vantagem: minha intimidade com a autora. O exame dos textos, postulam hoje os especialistas, deve ignorar a mão que os redigiu (tensa, não obstante, de história e de motivos obscuros). (LINS, 2005, p. 10)

Osman Lins contrapõe-se não apenas a uma prática docente de leitura, mas ainda à própria delimitação dos estudos estruturalistas, centrados na análise das relações entre as unidades compositivas do texto literário (tal como Barthes realizou em sua interpretação do conto O caso do sr. Valdemar, de Edgar Allan Poe), colocando no exílio aspectos biográficos e sociológicos, que orientam outras modalidades da crítica. Ao estudioso estruturalista, conforme diz Todorov, não é a "obra literária em si mesma" nem o seu autor que interessam, mas as "propriedades desse discurso particular que é o discurso literário. Qualquer obra só é considerada, então, como a manifestação de uma estrutura abstrata mais geral, de que não é mais que uma das realizações possíveis" (TODOROV, 1971, p. 15). 
Leyla Perrone Moisés, por sua vez, diz que "o estruturalista literário procura extrair da obra particular as estruturas gerais de um gênero, de um movimento ou de uma literatura nacional; visa, portanto, ao estabelecimento de modelos" (TODOROV, 2006, p. 10), para a partir daí poder aplicá-los ao estudo das obras particulares, apontando o que essas têm de singular "aquilo que fica para fora do molde é o específico, o original, o elemento gerador de transformações ulteriores" (idem).

A poética estrutural afastou-se da noção de personagem como essência ou sujeito psicológico para relacioná-lo às ações desenvolvidas na narrativa (por este motivo o personagem é chamado de actante por Greimas e outros teóricos), seguindo o caminho iniciado por Propp em seu estudo dos contos folclóricos russos. O estudo da biografia do autor, que orientava o ensino tradicional de literatura nas escolas francesas, foi banido pelos estruturalistas, como algo irrelevante - interdição ironizada por Osman Lins em diversas passagens do romance, como nesta: "Posso indagar ainda: assente que o autor não existe, teria eu sido amante de ninguém?" (LINS, 2005, p. 11).

Não por acaso, o narrador de $A$ Rainha dos Cárceres da Grécia se apresenta como um professor de biologia, e não como um crítico literário: logo, é um especialista em estruturas da vida, não em estruturas literárias (se é possível sustentar tal dicotomia, já que um romance, por maior que seja sua aproximação com a realidade imediata e aparente dos fenômenos, é sempre uma construção verbal, e a "vida" permanece algo exterior à obra de arte). Esse dialogismo é a coluna vertebral do livro de Osman Lins, e se apresenta sob diversas formas, desde alusões e referências explícitas até formas mais sutis de paródia, pastiche, ironia e metáfora, em sua análise da construção da narrativa de $A$ Rainha dos Cárceres da Grécia.

O livro de Júlia Marquezim Enone, conforme diz o narrador, permaneceu inédito, sendo recusado por diversas 
editoras; as únicas cópias existentes, feitas por mimeógrafo, foram distribuídas pelo narrador a um grupo seleto de pessoas. Logo, trata-se de uma obra em situação excêntrica, deslocada do "sistema literário" (que pressupõe um público) e do âmbito de discussão acadêmica. O narrador inicia sua análise fazendo um resumo do enredo do romance (embora de maneira distinta daquela praticada por Todorov, em sua metodologia para a codificação de uma "gramática narrativa" do Decameron, de Bocaccio), mesmo considerando que esta é "uma prática superficial" que "difunde e reanima a idéia corrente segundo a qual a história é o romance, não um de seus aspectos" (idem, 16).

Ele tem ciência de que "nasce o romancista com o ato de dispor esses eventos e de elaborar uma linguagem que não sabemos se os reflete ou se apenas serve-se deles para existir" (idem), e também de que o romance é "construção verbal, feixe de alusões, laboratório de instrumentos, campo de provas de materiais tanto novos como obsoletos" (idem, 46). No entanto, apresenta o resumo como ponto de partida de sua investigação, que ao longo do livro evolui, como reflexão metalinguística, iluminando diferentes aspectos do processo de criação. É possível identificar nessa exposição temática e em sua tessitura estilística não apenas informações sobre o enredo e o projeto estético do romance de Júlia Marquezim Enone, mas também sua visão sobre a literatura e as relações desta com o conceito de realidade.

A personagem central do romance é Maria de França, nordestina filha de lavradores que imigra para o Recife, onde trabalha como operária e empregada doméstica. Analfabeta, tem poucas chances de ascensão social; após sofrer de distúrbios mentais, passa por períodos de internação num hospital psiquiátrico, e enfrenta as rotinas burocráticas da Previdência Social para tentar conseguir a aposentadoria por invalidez. $\mathrm{O}$ nome Maria de França é também uma tradução literal de Marie 
de France, personalidade que, com "setecentos anos de distância (...) escreve na Inglaterra os seus lais e dedica-os a Henrique II, Plantageneta" (LINS: 2005, p. 114-115). A atribuição de um nome aristocrático a uma personagem humilde funciona, assim, como um irônico oxímoro.

A anti-epopéia da personagem, narrada numa prosa simples, com poucos artifícios de linguagem, aproxima-se da narração de cunho naturalista (e não faltam citações de textos jornalísticos sobre a crise do sistema previdenciário, informações sobre o contexto histórico e uma abordagem quase sociológica, além da descrição minuciosa de aspectos de sua vida doméstica). Porém, esta é apenas uma das camadas de leitura e compreensão do texto, o que é observado pelo próprio narrador que descreve e analisa o romance de sua amante:

o livro de Júlia Marquezim Enone, sob as espécies, digamos, de um figurativismo banal, oculta soluções incomuns e que afetam, longe do que pode sugerir o resumo, a visão corrente do real e dos processos narrativos, conforme haveremos de ver (idem, 46).

Em outra passagem da obra, o autor diz:

Júlia Enone faz uma concessão ao verossímil e assim fica livre para as experiências que, solerte, desejava pôr em prática no campo do romance. A loucura de Maria de França (...) é antes de tudo uma cortina para esconder a partida verdadeira, essencial, desenvolvida no campo da criação romanesca (...). Chave essencial na estrutura enganosa do livro, máscara da romancista, faz passar por deformação o que é tentativa de aprofundamento e por arbitrário o que é cálculo (idem, 127).

A Rainha dos Cárceres da Grécia, apesar de seu aparente naturalismo, coloca em xeque noções lineares de tempo e espaço, imprescindíveis ao mimetismo próprio da ficção 
regida por normas clássicas. A narrativa transcorre na cidade de Recife; porém, a autora transforma o ambiente de sua ficção, convertendo-o numa "estrutura móvel, que se desconjunta e sem cessar reordena-se" (idem, 118); Júlia Enone "remove a cidade de Olinda, anula os seis quilômetros que a distanciam do Recife e faz com que ela invada a capital, trespasse-a" (idem), criando uma "topografia mutável da cidade invadida, com os seus logradouros que flutuam e ligam-se a outros - separandose depois para novas combinações impossíveis" (idem). Como resultado dessa operação imaginativa, surge um "espaço híbrido" onde "há um espaço firme e um espaço móvel" (idem, 119), que constitui não um locus geográfico real, mas o campo inventado da narrativa.

A subversão espacial tem uma correspondente no plano temporal: segundo o narrador, "sobrepõem-se o hoje e o ontem simultâneos. As fachadas lisas das construções recentes coexistem com o geométrico entrelaçamento dos mudéjares; as paredes revestidas, com os muros vermelhos de adobe" (idem, 129). O tempo é híbrido, como o espaço; é o tempo ficcional, lúdico, não uma época histórica precisa. A fusão de tempos históricos e a reinvenção do espaço, porém, não são apenas experimentos narrativos, mas também cumprem uma função, no plano simbólico: a autora faz um paralelo entre as invasões holandesas no Nordeste brasileiro, no século XVII, e outras situações de violência, humilhação e espoliação de épocas subsequentes - e lembremo-nos que o romance foi escrito durante o regime militar no Brasil e os conflitos armados no Sudeste Asiático, em plena Guerra Fria.

A constante referência, no romance de Júlia Enone, a "soldados", "mosquetes" e outras palavras do léxico militar permitem esse tipo de leitura e realçam a relação entre literatura e realidade defendida pelo autor, ainda que dentro de uma complexa alegoria narrativa, que vai além do recorte histórico 
e não raro mescla o real com o imaginativo, tornando frágil a fronteira entre os dois campos. Ou ainda, como diz o romancista,

Transitam as personagens em um espaço simultaneamente real e irreal, que o estado mental de Maria de França justifica ou simula justificar: A Rainha dos Cárceres da Grécia, insisto, é um tecido de simulações. Talvez, como num jogo de reflexos (obtido, é verdade, com espelhos embaçados e em corredores sombrios), tenha perpassado no meu texto o espectro dessa operária e doméstica, atravessando consultórios e repartições, cruzando ruas não imaginárias de uma cidade real, o Recife, com seus rios e pontes (...). Neste processo de desvendamento que é o meu comentário (...) não foi ainda possível revelar o verdadeiro espaço da história, na verdade um Recife que não nega o Recife real e também não se limita ao modelo: enruga-o e encanta-o (idem, 117).

No livro de Júlia Marquezim Enone, que é o livro de Osman Lins, os planos da realidade e do simbólico estão indissoluvelmente ligados, permitindo ao leitor que se movimente por diferentes vias de decodificação, como numa espécie de jogo ou brincadeira - e podemos citar aqui a vinculação entre $A$ Rainha dos Cárceres da Grécia e os princípios da quiromancia, representada, de maneira cifrada ou enigmática, em diversas peripécias e na equivalência entre os seus cinco capítulos com os dedos das mãos e astros do zodíaco.

A analogia entre o romance de Júlia Marquezim Enone e as artes divinatórias, e em especial a quiromancia, está presente inclusive nos nomes dos personagens do livro, que remetem a místicos, reais ou lendários, ligados a essas técnicas esotéricas: Rônfilo, por exemplo, assemelha-se de modo especular a Ronphile, "quiromante famoso no século XVIII por ter previsto que Maria Antonieta, pouco antes dos quarenta anos, 'perderia os cabelos e não voltará a usar brincos" (idem, 35). 
O sentido paródico dessas referências e palimpsestos semânticos é evidente, e vai além de especulações de caráter esotérico: o labirinto formado pela somatória de alusões e enigmas é uma crítica irônica e metalinguística aos procedimentos cifrados de obras literárias de caráter experimental publicadas na primeira metade do século XX, que, assim como as formulações teóricas estrutruralistas, privilegiam a construção formal da obra literária.

O tempo histórico, neste romance construído em camadas superpostas, é uma dimensão alegórica e paródica, condição que permite traçarmos um paralelo com o Ulisses, de James Joyce: enquanto o autor irlandês transportou deuses e heróis gregos da Odisséia de Homero para a cidade de Dublin, no ano de 1904, convertidos em prostitutas, cafetinas, bêbados e fracassados, Júlia Enone inseriu "grandes vultos" da história brasileira em sua Recife recriada, cumprindo funções administrativas ordinárias no universo burocrático: "Ressurge o Marechal de Ferro, sem poder, sem farda e sem patente, no contínuo Flor (...). Rui Barbosa - Barbosa Neto - (...) esqueceu a Campanha Civilista e transformou-se num fanático do militarismo" (idem, 181). A bufonaria dessacralizadora, que converte os "heróis da pátria" em figuras menores, degradadas, em contraste com os novos heróis da televisão e do esporte profissional, recorda as sátiras poéticas de Oswald de Andrade e Murilo Mendes, e ainda o conceito de carnavalização de Bakhtin, pela mistura de elementos "elevados" e "vulgares", pela redução das desigualdades sociais ou mesmo inversões hierárquicas operadas pela autora.

Essa mutação deformadora dos ícones nacionais prossegue na passagem do hospício, que Júlia Marquezim Enone povoa com ilustres literatos, convertidos em pacientes psiquiátricos: Machado de Assis, José de Alencar, Clarice Lispector, entre outros (e podemos fazer um paralelo aqui com 
o Inferno de Dante, habitado por filósofos, poetas e escritores de diferentes tempos históricos). Nessa inversão de valores, agora ligada ao campo das patologias mentais, a autora representa "a dissociação entre a consciência e a realidade", manifestada, por exemplo, na "linguagem postiça e idealizante dos românticos, em especial na de José de Alencar" (idem, 195), incluído, assim, numa categoria similar à de D. Pedro II, o Barão do Rio Branco e outras personalidades incensadas por uma falsa consciência distanciada da realidade social brasileira.

A paródia e a carnavalização, elementos essenciais na construção do romance, têm uma função crítica e invadem inclusive o campo semântico, com a imitação burlesca, caricatural, do jargão dos médicos (a "estilística das bulas") e dos advogados, categorias profissionais relacionadas à dura jornada de Maria de França em busca de sua aposentadoria. Temos aqui o recurso do pastiche ou paródia de estilo, realizado por meio de "alusões pervertidas ao léxico, ao tom e à fraseologia cultivada no setor onde outras personagens dominam, caracteriza-as a elas" (idem, 127), operação em que, segundo Fiorim, "o narrador desqualifica o estilo imitado no próprio movimento de imitação" (BRAIT, 2006, p. 187), realizando uma "contestação social e política" (NITRINI, 1997, p. 159) via linguagem: "Tratase de uma identidade entre a contestação do código linguístico e oficial e a contestação à lei oficial" (idem).

A subversão sarcástico-semântica dos discursos do poder tem como contraparte o "discurso da loucura" de Maria de França, que "finge dirigir-se (...) ao público de uma emissora de rádio" e imita "os clichês de linguagem comuns aos locutores, e certos esquemas típicos de programas radiofônicos" (LINS, 2005, p. 87); a personagem, dessa forma, "converte a vida em discurso (ou instaura, mediante o discurso, um simulacro de vida)" (idem, 108). Em seus monólogos alucinados, Maria de França adota um tom ora confessional e narrativo ora profético, 
constrói suas frases de maneira não-gramatical, como a fala espontânea das crianças, com um léxico popular, adotando por vezes aliterações, paronomásias, rimas, trocadilhos e outros recursos da linguagem poética. Assim, por exemplo, nesta passagem:

Ninguém me ama? Ninguém me quer? Quer, sim. Alô, ouvintes, ouçam, vocês estão por longe, fora do Globo da Morte, mas agora abro a porta de aço e vou até aí, meu homem e anjo ordena, vou de chapéu de palha e entro na ciranda, coroa de pessoas, dedos dados, jogo flores nos telhados, no rio e nas ruas do Recife (idem, 32).

Se o discurso de Maria de França causa estranheza por ser distante da dicção das elites sociais e da própria noção de "normalidade" discursiva, esse efeito é ainda maior quando intervém o Espantalho, criatura simbólica construída a partir de 27 outros personagens do livro e que é chamado por diferentes nomes, tais como Brisa, Vento Largo, a Torre, Chuvarada, entre outros - nomes que, como diz o narrador, "convergem, todos eles, para as noções de brandura, força, proteção, fecundidade e amplitude, atributos de um ser incomum, ligado ao bem e o único capaz de guardá-la dos pássaros" (idem, 155).

O Espantalho é uma figura alegórica; como tal, é uma figuração de conceitos abstratos, assim como a gata de estimação de Maria de França, chamada Mimosina ou Memosina (nome derivado da deusa grega Mnemosine), que representa o "esfacelamento da memória" (idem, 205). Em outra passagem, diz o autor: "Nessa faixa, esquecer não aparece como um fato monstruoso, um desvio, e sim como signo da erosão do mundo, do seu desgaste" (idem, 209). O tema do esquecimento, aliás, está conjugado com outro: a fuga do devir temporal (e logo da história), empresa absurda da ladra Ana, que recebe o 
apelido de "rainha dos cárceres da Grécia" por suas constantes fugas e retornos à prisão. A saga dessa rebelde contra o tempo é descoberta ao acaso por Maria de França, que a adota como heroína de uma revolta não iniciada nem concluída.

Em contraste com a dicção culta ou pedante de médicos e advogados, o Espantalho fala uma espécie de idioleto composto de "frases sem sentido, canções anônimas, anexins, parábolas, quadras, parlengas, enigmas, profecias e indagações metafísicas" (idem, 157), carnavalizando a linguagem: "Era uma vez um homem. Foi com um desejo, voltou com dois queijos; foi com dois pães, voltou com três irmãs; foi com três primas, voltou com quatro rimas; foi com quatro versos, voltou com cinco berços" (idem, 230). Sua função no romance, a princípio, seria a de proteger Maria de França e "dispersar os pássaros desmesurados" (idem, 158), mas a sua principal função é de cunho linguístico: "arremessar o seu discurso, de certo modo o vértice da obra, ponto de encontro de muitos temas nela dispersos e aquele onde a linguagem, chegando a romper, incidentalmente, com os significados, alça-se a um diapasão de rara intensidade" (idem, 158-159).

É a voz do Espantalho que assume o monólogo final do romance, marcado por um aparente fluxo de consciência joyceano e por uma linguagem saturada de neologismos e palavras-valise, à maneira do Finnegans Wake: "saímos por uma perna de pato, vamos por aí, ela e eu, o Báçira, em direção aos impossíveis limitíferos, ao erumavezífero, ao Recífero, às portas abertíferas, ao bacorífero" (idem, 231). Este discurso neológico, que funde as vozes do narrador e do Espantalho num único enunciador, é a conclusão inconclusa do romance, que não apresenta um desfecho, deixando a obra aberta para a multiplicidade de leituras e interpretações de seus leitores. 


\section{Referências Bibliográficas}

BAKHTIN, Mikhail. Problemas literarios y estéticos. Havana: Editoral Arte y Literatura, 1986.

BRAIT, Beth. Bakhtin, Outros Conceitos-Chave. São Paulo: Editora Contexto, 2006.

CHABROL, Claude. Semiótica narrativa e textual. São Paulo: Editora Cultrix, 1977.

LINS, Osman. A Rainha dos Cárceres da Grécia. São Paulo: Editora Companhia das Letras, 2005.

NITRINI, Sandra. Literatura Comparada - História, Teoria e Crítica. São Paulo: Edusp, 1997.

TODOROV, Tzvetan. As estruturas narrativas. São Paulo: Editora Perspectiva, 2006.

TODOROV, Tzvetan. Estruturalismo e poética. São Paulo: Editora Cultrix, 1971.

\section{Resumo}

A Rainha dos Cárceres da Grécia, de Osman Lins, é um romance construído na forma de diário que discute a própria arte romanesca, utilizando o dialogismo, a alegoria, a alusão, a citação, a colagem, a paródia e outras formas intertextuais.

\section{Abstract}

A Rainha dos Cárceres da Grécia by Osman Lins is a novel written as a diary, and discusses the crafts of writting a novel itself, by using dialogism, alegory, alusion and quotation, assemblage, parody, as well as other intertextual resources. 